\title{
KeaA, a Dictyostelium kelch-domain protein that regulates the response to stress and development
}

\author{
Luciana Mantzouranis, Raquel Bagattini, Glaucia M Souza*
}

\begin{abstract}
Background: The protein kinase YakA is responsible for the growth arrest and induction of developmental processes that occur upon starvation of Dictyostelium cells. yakA- cells are aggregation deficient, have a faster cell cycle and are hypersensitive to oxidative and nitrosoative stress. With the aim of isolating members of the YakA pathway, suppressors of the death induced by nitrosoative stress in the yakA- cells were identified. One of the suppressor mutations occurred in keaA, a gene identical to DG1106 and similar to Keap1 from mice and the Kelch protein from Drosophila, among others that contain Kelch domains.

Results: A mutation in keaA suppresses the hypersensitivity to oxidative and nitrosoative stresses but not the faster growth phenotype of yakA- cells. The growth profile of keaA deficient cells indicates that this gene is necessary for growth. keaA deficient cells are more resistant to nitrosoative and oxidative stress and keaA is necessary for the production and detection of CAMP. A morphological analysis of keaA deficient cells during multicellular development indicated that, although the mutant is not absolutely deficient in aggregation, cells do not efficiently participate in the process. Gene expression analysis using CDNA microarrays of wild-type and keaA deficient cells indicated a role for KeaA in the regulation of the cell cycle and pre-starvation responses.

Conclusions: KeaA is required for CAMP signaling following stress. Our studies indicate a role for kelch proteins in the signaling that regulates the cell cycle and development in response to changes in the environmental conditions.
\end{abstract}

\section{Background}

The social amoebae Dictyostelium discoideum grows as a unicellular organism feeding on soil bacteria. Upon nutrient depletion the amoebae survive by differentiating into spores in a developmental process where $10^{5}$ cells aggregate and differentiate to form a $1 \mathrm{~mm}$ tall organism with distinct tissues. cAMP is a molecule with multiple functions during the entire life cycle, acting both extracellularly as a chemoattractant and intracellularly as a regulator of gene expression. The protein kinase YakA has been implicated in the transition from growth to development, playing a crucial role in this process. YakA is an effector of the gene expression changes that follow starvation including the down-regulation of vegetative genes, the up-regulation of the cAMP-dependent protein kinase, $p k a C$, the adenylyl cyclase $a c a A$, and the

\footnotetext{
*Correspondence: glmsouza@iq.usp.br
}

Departamento de Bioquímica, Instituto de Química, Universidade de São

Paulo, Av. Prof. Lineu Prestes 748, B9 S, sala 954, 05508-000, São Paulo, Brasil
cAMP receptor carA. During growth YakA regulates the cell cycle, and the survival to oxidative, nitrosoative and thermal stresses. YakA impinges on the cell cycle by regulating the interval between cell divisions and the growth arrest that follows stress. PKA-C is also activated by YakA in response to treatment with compounds that generate nitric oxide and by $\mathrm{H}_{2} \mathrm{O}_{2}$ indicating that several stress responses in Dictyostelium are modulated by YakA/PKA [1-3].

PKA has been extensively characterized in Dictyostelium and has been implicated in the regulation of both early and late gene expression, the timing of cAMP production and cell differentiation and the coordination of fruiting body morphogenesis with the terminal differentiation of spores and stalk cells $[4,5]$. At the onset of development, PKA-C is required for the expression of key cAMP signaling proteins such as the aggregationstage adenylyl cyclase, ACA, and the major cAMP receptor, cAR1 $[6,7]$.
C Biomed Central

(c) 2010 Mantzouranis et al; licensee BioMed Central Ltd. This is an Open Access article distributed under the terms of the Creative Commons Attribution License (http://creativecommons.org/licenses/by/2.0), which permits unrestricted use, distribution, and reproduction in any medium, provided the original work is properly cited. 
In $S$. cerevisiae the cAMP-PKA pathway plays a central role in the responses to changes in glucose concentration and initiates the signaling process that leads to cellular growth and proliferation. Glucose binds to the Gpr1 receptor, which activates cAMP synthesis through the Gpa2 protein. Inactivation of PKA causes yeast cells to arrest proliferation and to enter into the stationary phase G0 [8-10]. Furthermore, the cAMP-PKA pathway negatively affects the $\mathrm{H}_{2} \mathrm{O}_{2}$ stress response [11] by a PKA-directed phosphorylation of Msn2/4 transcription factors, resulting in the inhibition of its stress-induced nuclear redistribution [12]. The cAMP-PKA pathway also has a negative effect on Yap1-dependent transcription through a mechanism that remains unrevealed. It was shown that a strain lacking the PKA regulatory subunit Bcy1 exhibits a strong inactivation of Yap1dependent transcriptional control, although increased levels of cAMP, capable of inhibiting Msn2/4, has no apparent effect on Yap1 pathway [13-15].

In the present work we describe a new component of the YakA/PKA pathway we called KeaA. KeaA is a member of the kelch-domain superfamily of proteins $[16,17]$ that includes more than 30 proteins found in humans, mice, Drosophila, C. elegans, Arabidopsis, rice, yeasts, viruses and others. The kelch domain is a motif of 44-56 amino acids commonly found repeated 5-7 times. Each motif forms a 4-stranded $\beta$-sheet tilted around a central axis as a $\beta$-propeller [18]. Its cellular functions are diverse. Members have been found that bind to actin, regulate cell morphology, modulate gene expression and mediate protein-protein interactions [17]. KeaA also presents a zinc-finger type $\mathrm{C} 3 \mathrm{HC} 4$ domain or RING-finger. Two different variants exist of this domain, the C3HC4-type and a C3H2C3-type, which are clearly related despite the different cysteine/ histidine sequence patterns. The RING-finger domain is a specialized type of $\mathrm{Zn}$-finger of 40 to 60 residues that binds two atoms of zinc and is probably involved in mediating protein-protein interactions [19]. Various RING finger proteins also exhibit binding to E2 ubiquitin-conjugating enzymes [20]. Conjugation reactions related to ubiquitination are essential for macroautophagy in Dictyostelium. Dictyostelium macroautophagy mutants do not show abnormalities during growth but fail to complete normal morphogenesis. Furthermore, the development of these mutants is more aberrant in plaques on bacterial lawns than on nitrocellulose filters [21].

A mutation in KeaA has been previously described by Loomis and colleagues http://www-biology.ucsd.edu/ others/dsmith/dictydb.html to affect Dictyostelium development. Our results are the first to indicate a role for KeaA, in the regulation of Dictyostelium growth and stress survival.

\section{Results}

keaA, a kelch-domain protein, suppresses yakA

Treatment of cells with $\mathrm{H}_{2} \mathrm{O}_{2}$ or SNP (sodium nitroprusside, a generator of nitric oxide), inhibits growth of wild-type cells with little loss of cell viability but causes death of yakA null cells [3]. To identify components that might modulate the nitrosoative/oxidative stress responses in Dictyostelium, yak $A^{-}$second site suppressors were isolated from a pool of insertion mutants treated with SNP. DNA from a confirmed SNP resistant clone was isolated, the mutated gene was cloned by plasmid rescue and its sequence determined. Gene DG1106, previously mutated by the Developmental Gene Program http://www-biology.ucsd.edu/others/ dsmith/dictydb.html and [Dictybase: DDB_G0271500], sequenced by the Dictyostelium Genome Project [22] were identical to the mutated gene. Similar proteins identified using the BLAST algorithm were the rat and mouse kelch-like protein 8 [Genbank:XP_213995], [Genbank:NP_848856], the Drosophila Diablo protein [Genbank:AAF43447], Keap1 [Genbank:BAA34639] and several other kelch proteins that contain a BTB/POZ domain. The gene codes for a kelch domain protein of 1207 amino acids with six kelch repeats at the C-terminus and a zinc-finger type $\mathrm{C} 3 \mathrm{HC} 4$ domain, also called RING finger, at the N-terminus. No BTB/POZ domain is evident. An additional feature is a cysteine-rich sequence located in the mid6 portion of the protein, between the RING-finger domain and the kelch repeats (Figure 1). Due to its similarity to kelch proteins, the isolated mutant was named $k e a A^{-}$and the gene keaA.

The levels of mRNA for keaA were compared between wild-type cells and keaAcells by quantitative PCR. Figure 2 shows that the levels of expression of keaA in keaAcells are around $80 \%$ lower when compared to the levels in wild-type cells. For these experiments we used the REMI mutant containing the insertion of the plasmid at the end of the gene - between the amino acids 1198 and 1199 . Similar results were obtained when DG1106 was analyzed (insertion at 1041).

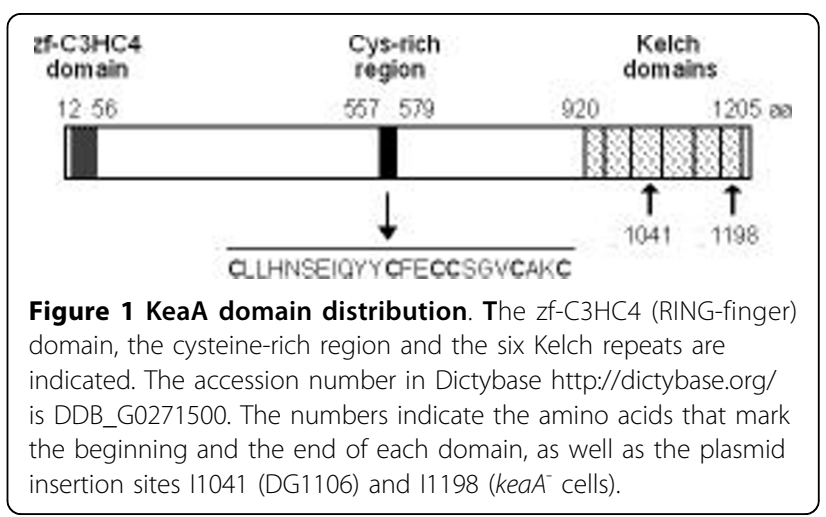




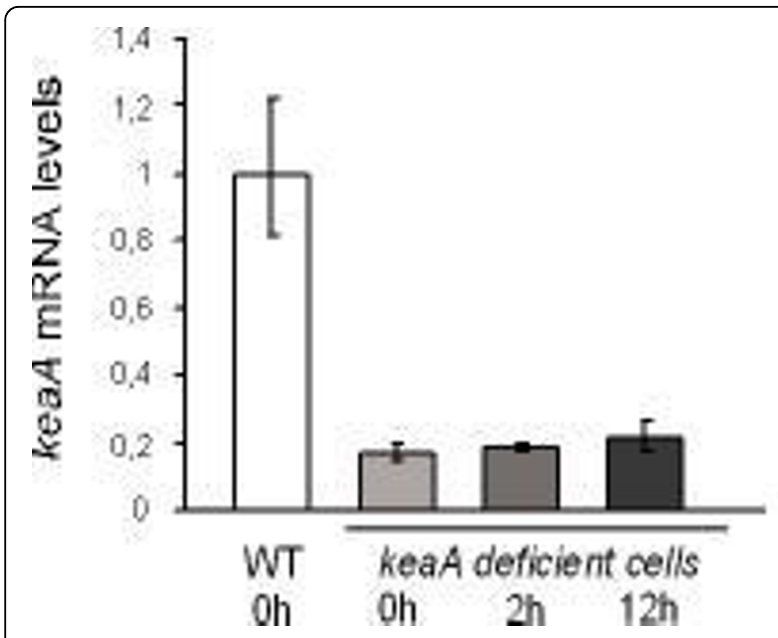

Figure 2 keaA expression in keaA deficient cells. Wild-type cells and keaA deficient cells were diluted to $0,5 \times 10^{6}$ cells $/ \mathrm{mL}$ in HL5, grown and collected when cells reached $1 \times 10^{6}$ cells $/ \mathrm{mL}$. This time point was considered the point $0 \mathrm{~h}$. keaA deficient cells were collected at the indicated times. The ratios are relative to transcript levels detected in wild-type cells at $0 \mathrm{~h}$.

In an effort to obtain a complete ablation of gene expression we designed a knockout vector containing $1 \mathrm{~kb}$ above the gene and $1 \mathrm{~kb}$ below the gene flanking the blasticidin resistance gene. The construct was introduced into Dictyostelium cells for deletion of the gene. After scanning hundreds of clones for phenotypical alterations 96 clones were evaluated for a deletion of the gene by PCR. We could not get any mutant that contained the construction recombined at the targeted site.

To confirm a role for $k e a A$ in the protection from stress responses the mutation was recapitulated by homologous recombination in the $y a k A / k e a A$ null background [23] and the survival rates of keaA deficient cells were scored after oxidative and nitrosoative stresses. Since YakA, PKA-C and AcaA have all been shown to have a role in the ability to survive nitrosoative and oxidative stresses [3] the null mutants for these genes were also analyzed. Wild-type, $k e a A^{-}, y a k A^{-}, p k a C^{-}, a c a A^{-}$and the double $y a k A^{-} / \mathrm{kea} A^{-}$cells were treated with $500 \mu \mathrm{M}$ SNP or $500 \mu \mathrm{M} \mathrm{H}_{2} \mathrm{O}_{2}$ for 24 hours. The drugs were then removed and the cells plated for colony scoring after growth in the presence of bacteria. As seen in Table 1, a mutation in keaA rescues the hypersensitivity of yakA- cells to both treatments. A comparison of yak $A^{-}$cells with the double mutant yak $A^{-} / k e a A^{-}$indicates that the double mutant shows higher survival rates. The single mutant $k e a A^{-}$shows higher survival rates than those observed for wild-type cells as was also observed for $p k a C^{-}$and $a c a A^{-}$cells.

yak $A^{-}$cells have been shown to have a faster cell cycle. To determine if a mutation in keaA might suppress this
Table 1 Survival of cells submitted to nitrosoative and oxidative challenges

\begin{tabular}{|c|c|c|}
\hline Strain & Treatment & $\%$ survival \\
\hline Wild-type & SNP $24 \mathrm{~h}$ & $86.3+/-4.2$ \\
\hline pkaC & SNP $24 \mathrm{~h}$ & $96.3+/-2.1$ \\
\hline$a c a A^{-}$ & SNP $24 \mathrm{~h}$ & $96.0+/-2.7$ \\
\hline yak $A^{-}$ & SNP $24 \mathrm{~h}$ & $31.7+/-6.2$ \\
\hline$k e a A^{-}$ & SNP $24 \mathrm{~h}$ & $90.4+/-3.8$ \\
\hline yakA/keaA & SNP $24 \mathrm{~h}$ & $88.1+/-3.6$ \\
\hline Wild-type & $\mathrm{H}_{2} \mathrm{O}_{2} 24 \mathrm{~h}$ & $70.2+/-4.8$ \\
\hline pkaC & $\mathrm{H}_{2} \mathrm{O}_{2} 24 \mathrm{~h}$ & $90.8+/-2.6$ \\
\hline$a c a A^{-}$ & $\mathrm{H}_{2} \mathrm{O}_{2} 24 \mathrm{~h}$ & $94.6+/-2.9$ \\
\hline yak $A^{-}$ & $\mathrm{H}_{2} \mathrm{O}_{2} 24 \mathrm{~h}$ & $18.9+/-3.2$ \\
\hline$k e a A^{-}$ & $\mathrm{H}_{2} \mathrm{O}_{2} 24 \mathrm{~h}$ & $100.0+/-4.3$ \\
\hline yakA /keaA & $\mathrm{H}_{2} \mathrm{O}_{2} 24 \mathrm{~h}$ & $88.1+/-3.7$ \\
\hline
\end{tabular}

Exponentially growing cells were diluted to $1 \times 10^{6}$ cells $/ \mathrm{ml}$ and incubated with $500 \mu \mathrm{M}$ SNP or $500 \mu \mathrm{M} \mathrm{H}_{2} \mathrm{O}_{2}$ for $24 \mathrm{~h}$. Cells were counted and plated in association with Klebsiella aerogenes for colony number scoring. The percentage of survival is relative to the untreated control. The results are significant of six independent experiments.

phenotype growth curves were performed. Figure 3A shows a growth curve of wild-type, kea $A^{-}$, yak $A^{-}$and yak $A^{-} / k e a A^{-}$cells. The double mutant yak $A^{-} / k e a A^{-}$ shows growth rates similar to $y a k A^{-}$cells, indicating that the faster cell cycle phenotype of $y a k A^{-}$is not suppressed by a mutation in $k e a A$, whereas $y a k A$ appears as a suppressor of keaA null cells for growth. Also, the growth profile of keaA deficient cells indicates that this gene is necessary for growth. The approximate doubling time for keaA deficient cells during exponential growth is 20-24 h while for wild-type cells it is around $8 \mathrm{~h}$. This growth deficiency is even more pronounced when cells are diluted to very low density (under $10^{5} / \mathrm{mL}$ ). Under these conditions the doubling time rises to $40 \mathrm{~h}$ and frequently no growth is observed. A slower growth is also observed when cells are plated in the presence of Klebsiella aerogenes. Wild-type colonies take around 42 hours to appear on plates while keaA deficient cells take an additional 12 hours to do so.

yak $A^{-}$cells lyse under prolonged incubation in the presence of SNP and $\mathrm{H}_{2} \mathrm{O}_{2}$. This has been interpreted as a lack of ability to arrest growth under these conditions. To access if a mutation in keaA prevented such extensive damage, growth curves were performed for wild-type, $k e a A^{-}, y a k A^{-}$and $y a k A^{-} / k e a A^{-}$cells incubated in the presence of SNP (Figure 3B) and $\mathrm{H}_{2} \mathrm{O}_{2}$ (Figure 3C) for more than 5 days. As seen in the figures, a mutation in keaA suppresses yak $A^{-}$cell death induced by SNP and $\mathrm{H}_{2} \mathrm{O}_{2}$. The SNP-treated double mutant yakA-/keaA- shows a growth profile similar to treated wild-type cells and no extensive lysis is observed. Similarly, no lysis is observed when the double mutant was treated with $\mathrm{H}_{2} \mathrm{O}_{2}$. The keaA deficient cells show a slower growth under 
A.

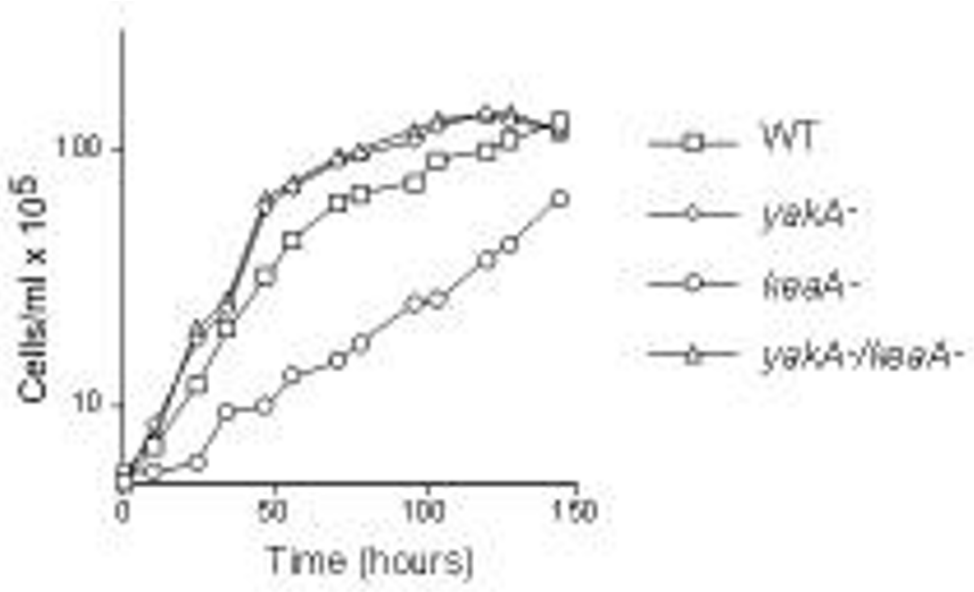

B.

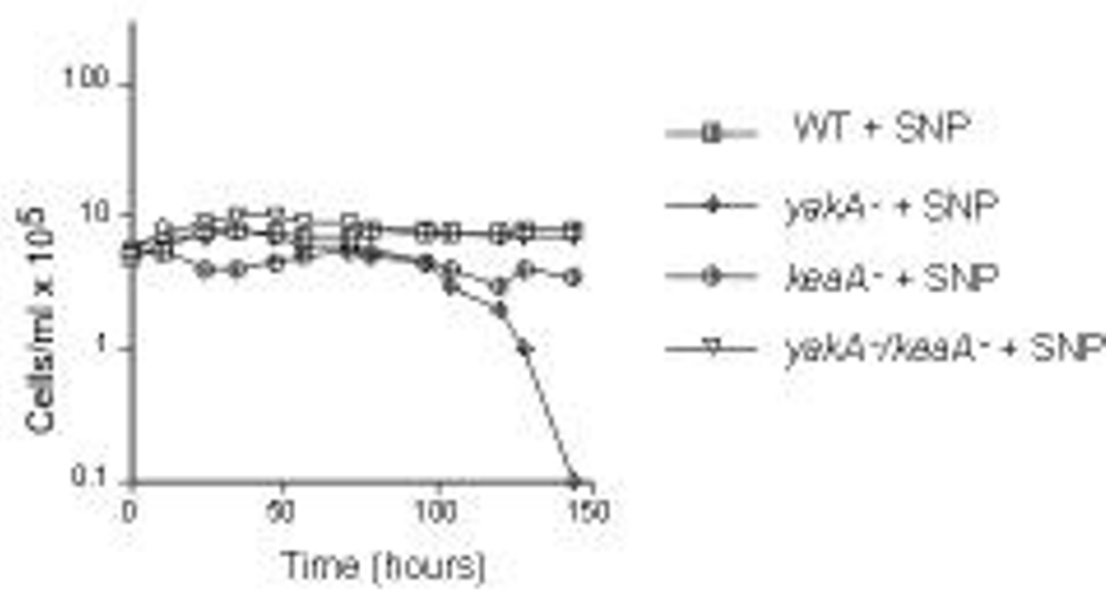

C.

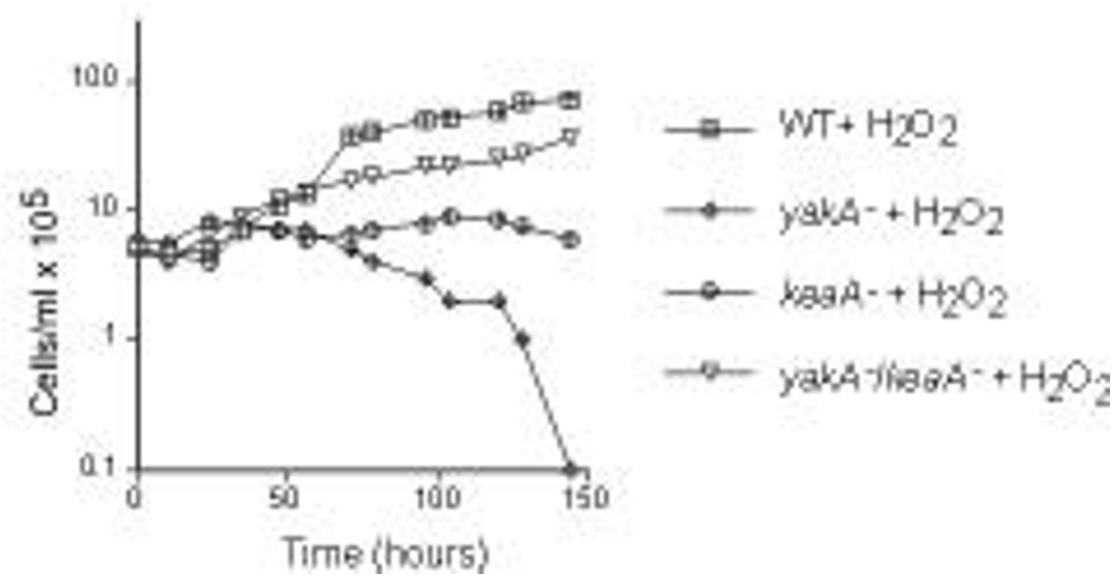

Figure 3 keaA suppresses yakA death induced by SNP and $\mathrm{H}_{2} \mathrm{O}_{2}$. Cells were diluted to $5 \times 10^{5} \mathrm{cells} / \mathrm{mL}$ and incubated at $22^{\circ} \mathrm{C}$ in the absence (A) or presence of $500 \mu \mathrm{M} \mathrm{SNP}$ (B) or $500 \mu \mathrm{M} \mathrm{H}_{2} \mathrm{O}_{2}$ (C). Cells were counted at the indicated times. Data corresponding to yakA- and yakA'/keaA overlap. 
prolonged SNP and $\mathrm{H}_{2} \mathrm{O}_{2}$ treatment when compared to wild-type cells. This would lead us to conclude that keaA minus cells are more hypersensitive to these treatments when compared to wild-type cells. But since this mutant shows impaired growth under axenic conditions in the absence of treatments, it is difficult to compare the protective role for the mutation in axenic growth. We thus decided to plate for growth in the presence of bacteria, after removal of the challenge. Under this conditions the protection is apparent since keaA deficient cells show higher survival rates than those observed for wild-type cells in both treatments (Table 1).

\section{$k e a A$ expression is regulated during growth and development}

To verify if keaA expression is regulated during development, wild-type cells were starved in nitrocellulose filters and the cells were collected after 2 and 12 hours. Transcript levels analysis by quantitative PCR (Figure 4A) indicates an induction upon starvation. keaA expression was also analyzed in wild-type cells during growth (Figure 4B). Wild-type cells were grown in the presence of bacteria and collected by differential centrifugation after 44, 47 and 50 hours. At $50 \mathrm{~h}$ the bacterial lawn was cleared and development started. The results indicate that an induction of keaA also occurs as the cells grow and the food source becomes scarce.

\section{KeaA is required for the production and detection of cAMP}

We have shown that SNP and $\mathrm{H}_{2} \mathrm{O}_{2}$ treatments induce cAMP production [3]. Mutants that lack the ability to synthesize cAMP, such as $p k a C^{-}$and $a c a A^{-}$cells are more resistant to oxidative and nitrosoative stresses. To determine if the observed resistance of keaA deficient cells to nitrosoative and oxidative stresses was related to a deficiency in cAMP synthesis, the levels of this cyclic nucleotide were measured in keaA deficient cells (Table 2). SNP and $\mathrm{H}_{2} \mathrm{O}_{2}$ treatments induce cAMP accumulation in wildtype cells but the induction is not significant in $y a k A^{-}$, $a c a A^{-}$and keaA deficient cells. This indicates that these genes are necessary for cAMP production in response to these stresses.

To further investigate a role for $k e a A$ in the regulation of cAMP metabolism, wild-type and keaA deficient cells were starved in phosphate buffer in liquid suspension for $2 \mathrm{~h}$ and then stimulated with $80 \mathrm{nM}$ cAMP every 6 minutes for $4 \mathrm{~h}$. Table 3 shows the percentage of isolated cells counted for each cell line submitted or not to cAMP pulses. Over $80 \%$ of the wild-type cells were found in aggregates after $6 \mathrm{~h}$ and this number increased to $95 \%$ when cAMP pulses were added. In the case of keaA deficient cells, $62 \%$ were aggregated after $6 \mathrm{~h}$, and addition of cAMP increased the aggregated cell

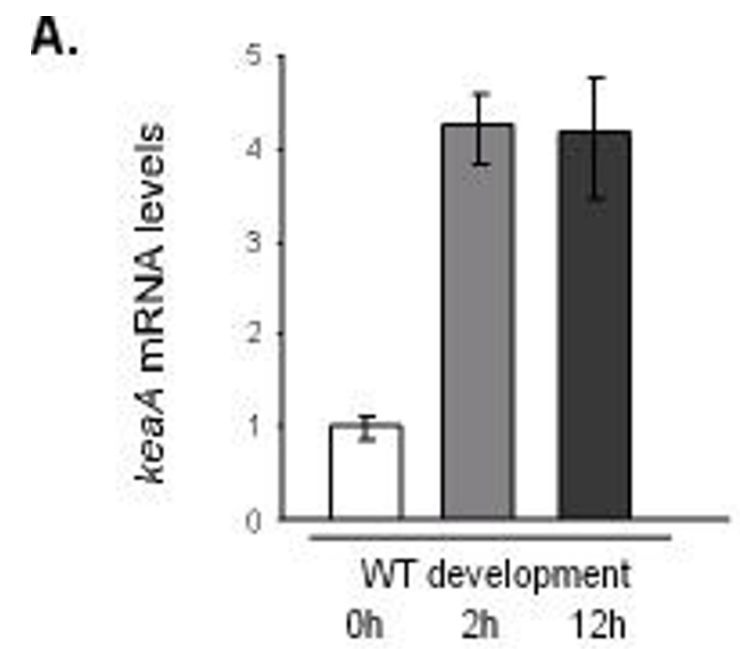

B.

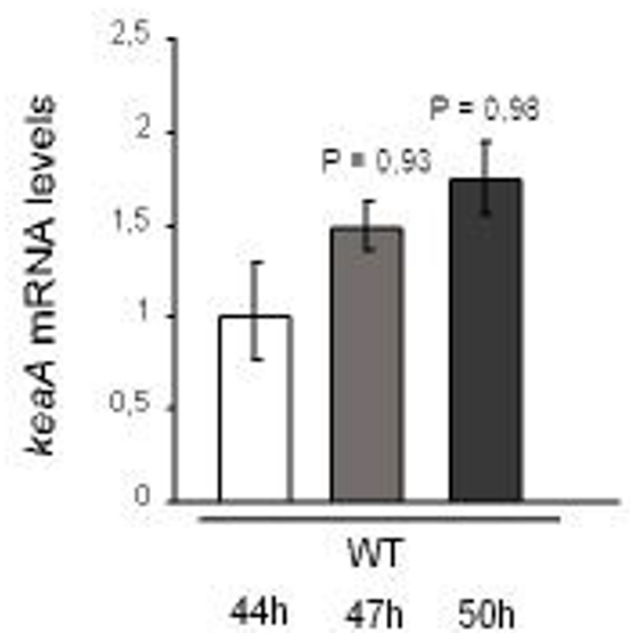

Figure 4 keaA expression is induced by growth and development. Quantitative PCR was used to determine keaA expression levels during growth and development. (A) Wild-type cells were developed on phosphate buffer on Millipore filters and collected after 2 and 12 hours of development. The point $0 \mathrm{~h}$ represents wildtype cells in the early exponential phase of growth. The ratios are relative to transcript levels detected at $0 \mathrm{~h}\left(1 \times 10^{6}\right.$ cells $\left./ \mathrm{mL}\right)$. (B) Wildtype cells were grown in the presence of bacteria and collected by differential centrifugation after 44,47 and 50 hours from plating. At 50 $\mathrm{h}$ plates were cleared of bacteria and development started. The ratios are relative to transcript levels detected at 44 hours. The $P$ value was calculated in relation to the sample $44 \mathrm{~h}$ (reference sample). The results are representative of four different experiments.

population to $71 \%$. Thus, the addition of cAMP pulses can stimulate aggregation of wild-type cells more efficiently than of keaA deficient cells, indicating that the mutant cells are less responsive to cAMP pulses.

\section{KeaA is required for aggregation}

A morphological analysis of keaA deficient cells during multicellular development indicated that, although this 
Table 2 cAMP measurements of cells submitted to nitrosoative and oxidative challenges

\begin{tabular}{|c|c|}
\hline Strain & pmol cAMP $/ 10^{7}$ cells \\
\hline Wild-type & $0.95+/-0.15$ \\
\hline Wild-type + SNP & $2.35+/-0.45$ \\
\hline Wild-type $+\mathrm{H}_{2} \mathrm{O}_{2}$ & $1.85+/-0.22$ \\
\hline$a c a A^{-}$ & $1.02+/-0.36$ \\
\hline$a c a A^{-}+S N P$ & $0.70+/-0.02$ \\
\hline$a c a A^{-}+\mathrm{H}_{2} \mathrm{O}_{2}$ & $0.88+/-0.03$ \\
\hline yakA- & $1.11+/-0.20$ \\
\hline yakA- + SNP & $1.15+/-0.15$ \\
\hline yakA- $+\mathrm{H}_{2} \mathrm{O}_{2}$ & $1.08+/-0.06$ \\
\hline $\mathrm{keaA}^{-}$ & $1.01+/-0.08$ \\
\hline$k e a A^{-}+S N P$ & $1.32+/-0.27$ \\
\hline$k e a A^{-}+\mathrm{H}_{2} \mathrm{O}_{2}$ & $1.26+/-0.16$ \\
\hline
\end{tabular}

Exponentially growing cells were diluted to $1 \times 10^{6}$ cells $/ \mathrm{ml}$ and incubated with $500 \mu \mathrm{M} \mathrm{SNP}$ for $24 \mathrm{~h}$ or $\mathrm{H}_{2} \mathrm{O}_{2}$ for $12 \mathrm{~h}$. Cells were counted, aliquots of $5 \times 10^{6}$ cells were collected and the cell pellets were frozen for cAMP measurements. The values represent the mean $+/$ - s.e.m. for 3 independent experiments.

gene is not absolutely required for aggregation, it is required for the cells to efficiently participate in the process. Loomis described DG1106 as an aggregation minus strain after screening of colonies in agar plates. Their screening may have missed small fruiting bodies formed at a later developmental time. Figure 5A shows a detail of a wild-type and a keaA deficient cell colony. Wildtype cells show a defined colony border at the interface of the bacterial front, which is followed by aggregating cells, and more to the center of the colony, culminants and fruiting bodies. keaA deficient cell colonies are diffuse and no clear definition of the borders are seen. The region next to the bacterial front, which in wild-type cells contains aggregating cells, is devoid of aggregates. Aggregates are seen more to the center of the colonies and fruiting bodies are smaller and take longer to appear. The delay in aggregation is evident when development was observed on clearing plates. Cells were plated in the presence of Klebsiella aerogenes and the time to the major morphological changes during multicellular development was observed (Figure 5B). For wild-type cells ruffling was observed after $61 \mathrm{~h}$ from plating,

\section{Table 3 Stimulation of aggregation by CAMP pulses}

\begin{tabular}{lr}
\hline Strain & \% of isolated cells \\
\hline Wild-type & $20.1+/-2.5$ \\
Wild-type + CAMP & $5.6+/-1.6$ \\
$k e a A^{-}$ & $38.6+/-3.1$ \\
$k e a A^{-}+$CAMP & $29.2+/-2.7$ \\
\hline Wild-type and $k e a A^{-}$cells were washed, ressuspended in phosphate buffer to \\
$1 \times 10^{7}$ cells/ml and starved in liquid suspension for 2 hours. At this point 80 \\
nM of cAMP was added every 6 minutes for 4 hours. The number of isolated \\
cells was counted and the percentage to the total number of cells was \\
calculated.
\end{tabular}

culminants after $66 \mathrm{~h}$ and fruiting bodies after $73 \mathrm{~h}$. For keaA deficient cells, ruffling took $12 \mathrm{~h}$ longer; once aggregated, the culminants took $15 \mathrm{~h}$ to appear and fruiting bodies another $9 \mathrm{~h}$ to form. Overall, the complete process took $97 \mathrm{~h}$ to completion in keaA deficient cell lines, while for wild-type cells fruiting bodies were observed after $73 \mathrm{~h}$ from plating with bacteria.

The delay in aggregation appears to be dependent on the starvation conditions. When cells were starved on phosphate/agar the difference in aggregation timing was greatly diminished. Figure 6A shows the formation of wild-type spiral waves after $8 \mathrm{~h}$ from plating in phosphate/agar. For keaA deficient cells, streams of migrating cells were observed after $12 \mathrm{~h}$. When plated on nitrocellulose filters the difference was smaller (Figure 6B). A delay of around $1 \mathrm{~h}$ is seen for keaA deficient cells to reach the tight aggregate stage. From then on, development seems to be very similar for both strains, with normal sized fruiting bodies being formed after $24 \mathrm{~h}$.

One of the differences between the plating methods described above is the cell density at which cells were starved. For the phosphate/agar experiments, cells were plated at approximately $4.4 \times 10^{5}$ cells $/ \mathrm{cm}^{2}$. For the nitrocellulose filter experiments cells were plated at approximately $31 \times 10^{5}$ cells $/ \mathrm{cm}^{2}$. To test if keaA deficient cells were more sensitive to the density at which they were starved, the time to aggregation was measured at different plating conditions (Table 4). Wild-type and keaA deficient cells were plated at $1,5,10$ and $25 \times 10^{6}$ cells/plate in phosphate/agar. These correspond to $0.18 \mathrm{cells} / \mathrm{cm}^{2}$, 0.9 cells $/ \mathrm{cm}^{2}, 1.8$ cells $/ \mathrm{cm}^{2}$ and 4.4 cells $/ \mathrm{cm}^{2}$ respectively. Wild-type cells were able to form tight aggregates when cells were plated at $0.90 \times 10^{5}$ cells $/ \mathrm{cm}^{2}$ or higher. keaA deficient cells were not able to aggregate at this cell density. At higher densities they took longer to aggregate than wild-type cells. The time taken to complete aggregation was increasingly longer than for wild-type cells with decreasing cell densities. Taken together the results seem to indicate that the aggregation deficiency phenotype observed for keaA deficient cells grown in the presence of bacteria is related to the low cell density at which the cells undergo starvation under these conditions.

Aggregation deficiency in low cell densities was described for cells that lacked proper cAMP signaling [24]. Mutants of the adenylyl cyclase AcaA that overexpressed $p k a C$ could not aggregate at low cell densities. Development of this strain was apparently normal though when the cells were plated at high cell density. To determine if components of the PKA/cAMP signaling pathway were being up regulated during aggregation as expected, the transcript levels for $p k a C$ and the cAMP receptor carA were determined by northern blots. Wild-type cells were plated in association with bacteria and collected after 56,61 , and 66 h. keaA deficient cells were collected 
A.

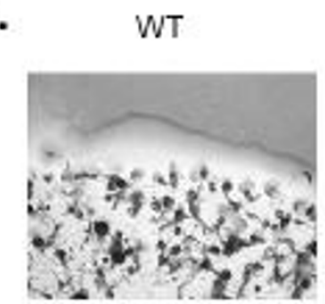

B. WT

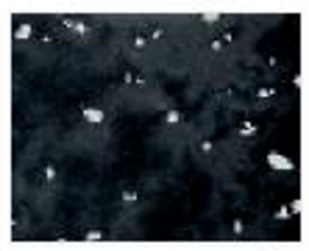

keaA deficient cells

$66 \mathrm{~h}$

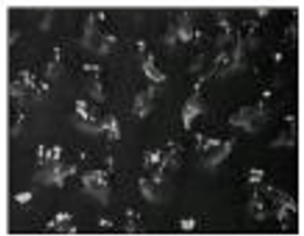

$73 h$

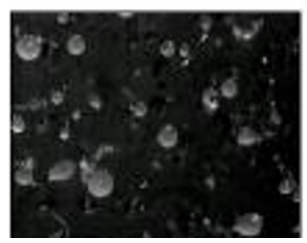

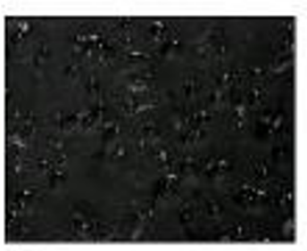
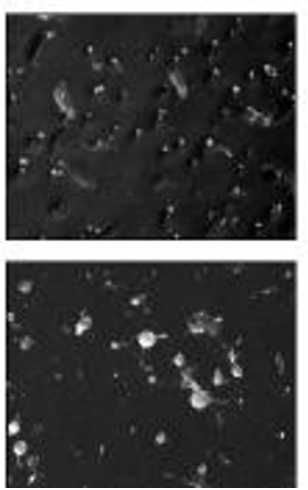

$73 h$
keaA deficient cells

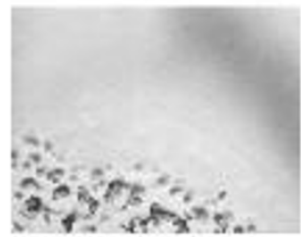

C.

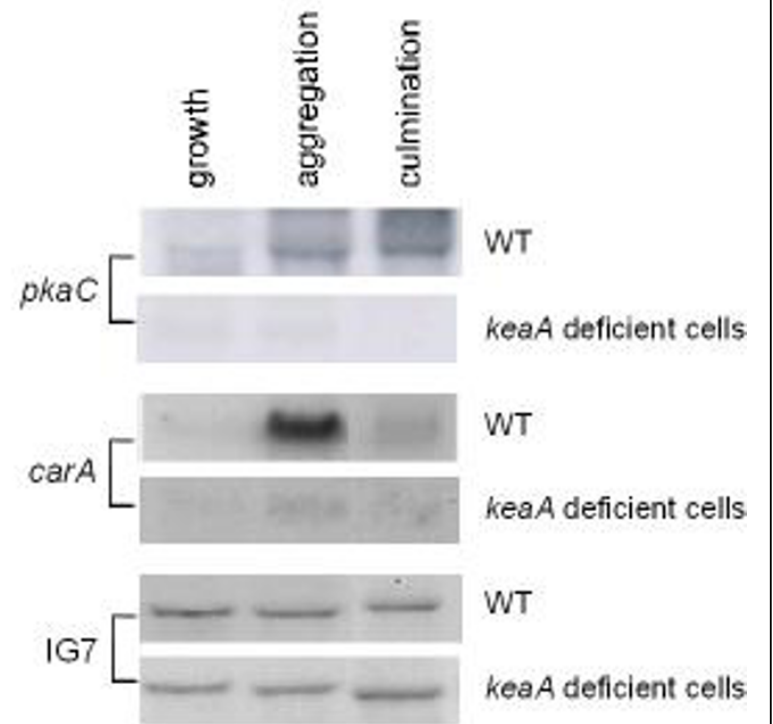

Figure 5 keaA deficient cells are aggregation deficient when grown in association with bacteria. Development was observed for wild-type and keaA deficient cells grown in agar in the presence of Klebsiella aerogenes. (A) A detail of the general appearance of the colonies is shown. (B) The time from clearing plate formation (beginning of starvation) to aggregation, culmination and fruiting body formation is shown from top to bottom. (C) Wild-type and keaA deficient cells clearing plates were prepared and cells were collected when they were growing, aggregating and culminating. Samples of total RNA were analyzed on northern blots using fragments of pkaC, carA and IG7, a constitutively expressed gene, as probes.

after $66 \mathrm{~h}, 73 \mathrm{~h}$ and $88 \mathrm{~h}$. At these time points they were growing, aggregating and culminating, respectively. Figure $5 \mathrm{C}$ shows that keaA deficient cells express low levels of $p k a C$ and $c a r A$ during aggregation and culmination when plated under low cell density conditions. Presumably carA levels are not increased due to the lack of PKA-C accumulation.

This may be the reason why these cells are delayed in the completion of these processes. This result was confirmed by quantitative PCR in cells developed in agar/ phosphate plates (Figure 7). Moreover, keaA deficient cells express higher levels of $d s c A$ when compared to wild-type cells, indicating that keaA may be required for the regulation of cAMP synthesis (Figure 7). The discoidins are cytoplasmic proteins expressed several generations before the onset of starvation by the extracellular "prestarvation factor" PSF [25] and by the secreted "conditioned media factor" CMF $[25,26]$. Several hours after the onset of development, transcription of the discoidin genes is down-regulated by cAMP via the cell surface receptor cAR1[27]. It appears that the downregulation of dscA is also dependent of KeaA.

When wild-type cells and keaA deficient cells were developed on nitrocellulose filters, the expression of $p k a C$ was increased during aggregation and culmination in both cell lines but with a delay in keaA deficient cells (Figure 6C). Therefore keaA is necessary so that an increase of $p k a C$ and carA occurs to normal levels during development especially under low-density conditions.

\section{cDNA Microarray}

In order to define gene expression changes of keaA deficient cells in response to oxidative and nitrosoative 
A.

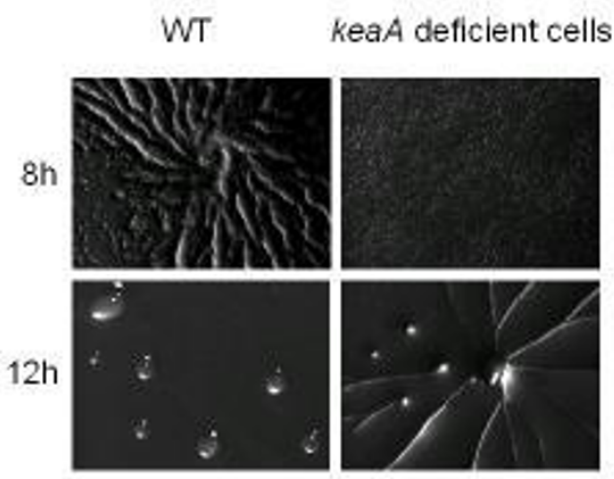

B.

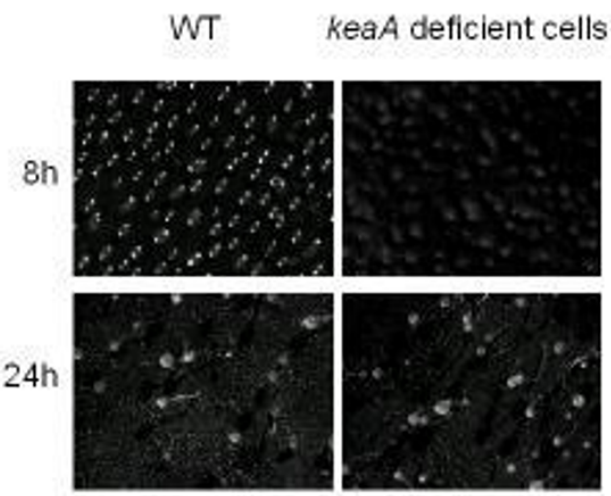

c.

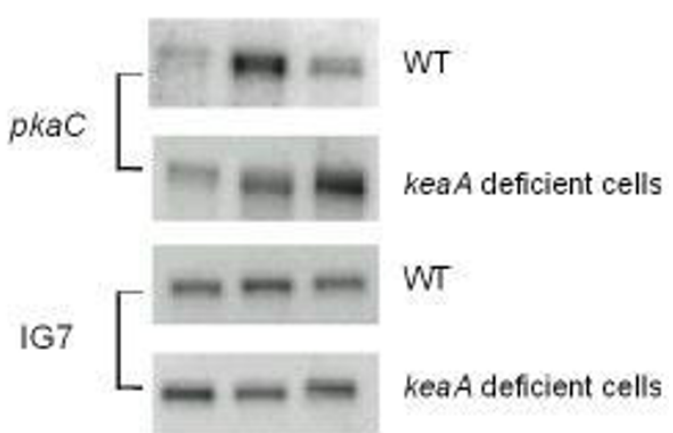

Figure 6 keaA deficient cells development is delayed when cells are starved in agar or filters. Development was observed for wild-type and keaA deficient cells developed in phosphate-agar (A) and nitrocellulose filters (B). The images were taken at the indicated time points of starvation. (C) Wild-type cells and keaA deficient cells were developed on nitrocellulose filters and collected when cells were growing, aggregating and culminating. Samples of total RNA were analyzed on northern blots using fragments of pkaC and IG7, a constitutively expressed gene, as probes.

stress and study in more detail the function and pathways regulated by $k e a A$, hybridizations were made using cDNA microarrays. Samples from wild-type cells and keaA deficient cells submitted to treatments with $\mathrm{H}_{2} \mathrm{O}_{2}$ or SNP were compared.

Data obtained using cDNA microarray was validated by qPCR. qPCR reactions were performed using samples

\section{Table 4 Time to aggregation at different cell densities.}

\begin{tabular}{|c|c|c|c|}
\hline Cells/plate & Cell density $\left(x 10^{5}\right.$ cells $\left./ \mathrm{cm}^{2}\right)$ & Wild-type & keaA \\
\hline $2.5 \times 10^{7}$ & 4.4 & $9 \mathrm{~h}$ & $12 \mathrm{~h}$ \\
\hline $1.0 \times 10^{7}$ & 1.8 & $11 \mathrm{~h}$ & $16 \mathrm{~h}$ \\
\hline $5.0 \times 10^{6}$ & 0.9 & $14 \mathrm{~h}$ & - \\
\hline $1.0 \times 10^{6}$ & 0.18 & - & \\
\hline
\end{tabular}

Exponentially growing cells were washed, ressuspended in phosphate buffer and plated over phosphate/agar $8,5 \mathrm{~cm}$ diameter plates to the cell densities indicated on the table. The developmental process was inspected and the time to the stage of tight aggregates was determined. The dash indicates no aggregation was observed for over $36 \mathrm{~h}$. from an independent experiment. Wild-type cells and keaA deficient cells were treated or not with $500 \mu \mathrm{M}$ SNP or $500 \mu \mathrm{M} \mathrm{H}_{2} \mathrm{O}_{2}$. Samples of $2 \times 10^{7}$ cells were collected, total RNA was extracted, and cDNAs were synthesized and hybridized to cDNA microarrays or submitted to qPCR reactions. Table 5 lists the differentially expressed genes. Figure 8 shows transcript levels for a selection of genes ( $d s c A, c s b B$ and $c y c B$ ) as detected by qPCR. $d s c A$ expression was induced in both wild-type cells and in keaA deficient cells. In response to 12 hours treatment with $\mathrm{H}_{2} \mathrm{O}_{2} d s c A$ expression is repressed in wild-type cells but induced in keaA deficient cells (Figure 8A). A very similar profile was observed for $c s b B$ transcripts which increased during growth both in wild-type cells and in keaA deficient cells and decreased in wild-type cells in response to treatment with $\mathrm{H}_{2} \mathrm{O}_{2}$ but not in keaA deficient cells (Figure 8B). 

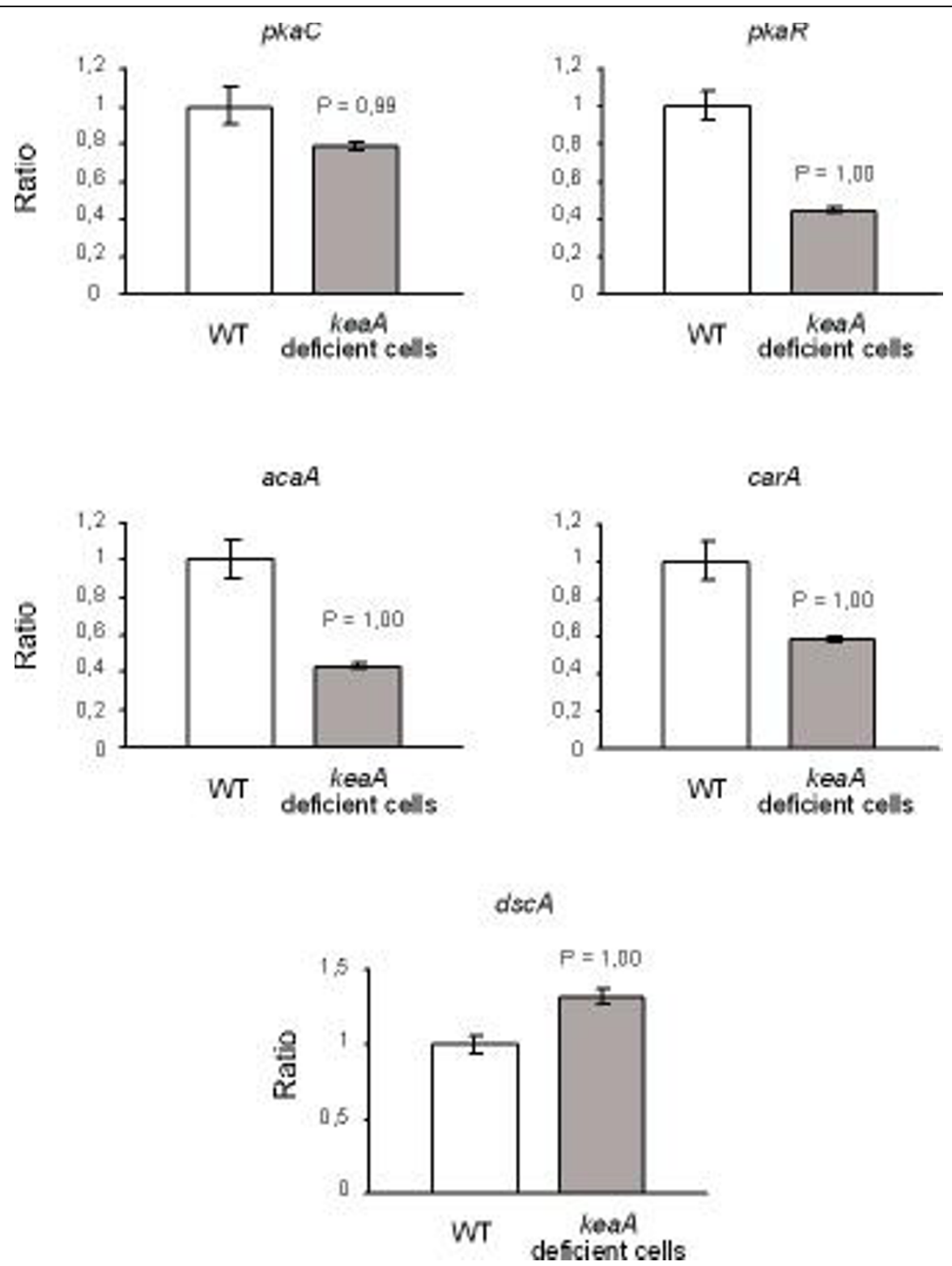

Figure 7 mRNA levels of development genes in cells submitted to starvation in phosphate/agar plates. Wild-type cells and keaA deficient cells were submitted to nutritional stress in phosphate/agar plates and collected after $8 \mathrm{~h}$. The ratios are relative to transcript levels detected in wild-type cells at $8 \mathrm{~h}$. The $\mathrm{P}$ value was calculated in relation to wild-type cells at $8 \mathrm{~h}$ (reference sample).

$c y c B$ expression was suppressed in response to treatment with SNP both in wild-type cells and in keaA deficient cells, but the decrease was more pronounced in wild-type cells than in keaA deficient cells. Treatment with $\mathrm{H}_{2} \mathrm{O}_{2}$ for 2 hours led to the repression of $c y c B$ in wild-type cells but in keaA deficient cells we observed increased levels of this gene's transcripts (Figure 9A and 9B).

\section{Discussion}

We have previously shown that stimulation of cells with $\mathrm{H}_{2} \mathrm{O}_{2}$, SNP or spermine NONOate, a generator of nitric oxide, inhibited growth of wild-type cells [3]. The same treatment led to extensive cell lysis and death of yakA null cells. $p k a C$ and $k e a A$ were isolated as suppressors of $y a k A$, in a screen targeted to reveal genes involved in the survival to nitrosoative stress [3]. Both genes are regulators of the starvation response. It appears that cAMP synthesis through the adenylyl cyclase AcaA is required for nutrient and nitrosoative/oxidative stress responses and that KeaA plays a role in these processes. A model that fits the findings of this and previous work is shown in Figure 10. keaA is necessary for cAMP synthesis in response to prolonged nitrosoative/oxidative stress (Table 2) and also for the increased mRNA levels 
Table 5 Gene expression profiling of wild-type and keaA deficient cells using cDNA microarrays

\begin{tabular}{|c|c|c|}
\hline & Wild type cells & keaA deficient cells \\
\hline $0 \mathrm{~h}$ growth $\times 2 \mathrm{~h}$ growth & - & - \\
\hline \multirow[t]{6}{*}{$0 \mathrm{~h}$ growth $\times 12 \mathrm{~h}$ growth } & crystal protein (cryS) $\uparrow$ & crystal protein (cryS ) $\uparrow$ \\
\hline & discoidin I, A chain (dscA) $\uparrow$ & discoidin I, A chain (dscA) $\uparrow$ \\
\hline & similar to protein kinase $C$ inhibitor $(p k i A) \uparrow$ & - \\
\hline & $12 \mathrm{kDa}$ protein $(c s b B) \uparrow$ & - \\
\hline & proteosomal alpha subuit 7-1 (prtB, M3R) $\uparrow$ & - \\
\hline & cytochrome c oxidase subunit VI (cxfA ) $\downarrow$ & - \\
\hline \multirow[t]{8}{*}{$2 \mathrm{~h}-\mathrm{SNP} \times 2 \mathrm{~h}+\mathrm{SNP}$} & penta EF hand calcium binding protein (pefA ) $\uparrow$ & - \\
\hline & culmination specific protein $45 \mathrm{D}(\mathrm{cul} / \mathrm{D}) \uparrow$ & - \\
\hline & cisteine protease $4(\mathrm{cprD}, \mathrm{CP} 4) \downarrow$ & - \\
\hline & ras GTPase-activating protein $\downarrow$ & - \\
\hline & DG1029 (Ras GAP1) $\downarrow$ & - \\
\hline & G2/M - specific cyclin B $(c y c B) \downarrow$ & - \\
\hline & - & putative calmodulin-binding protein CAM-BP15 $(\mathrm{cmbC}) \uparrow$ \\
\hline & - & flavohemoglobin $\uparrow$ \\
\hline \multirow[t]{3}{*}{$12 \mathrm{~h}-\mathrm{SNP} \times 12 \mathrm{~h}+\mathrm{SNP}$} & culmination specific protein $45 \mathrm{D}($ culD $) \uparrow$ & culmination specific protein $45 \mathrm{D}($ culD $) \uparrow$ \\
\hline & penta EF hand calcium binding protein (pefA) $\uparrow$ & penta EF hand calcium binding protein (pefA ) $\uparrow$ \\
\hline & calcium-binding protein $1 \uparrow$ & - \\
\hline \multirow[t]{15}{*}{$2 \mathrm{~h}-\mathrm{H}_{2} \mathrm{O}_{2} \times 2 \mathrm{~h} \mathrm{H}_{2} \mathrm{O}_{2}$} & glutathione reductase (gsr) $\uparrow$ & - \\
\hline & major vault protein $(m v p B) \uparrow$ & - \\
\hline & culmination specific protein $45 \mathrm{D}(\mathrm{cul} D) \uparrow$ & culmination specific protein $45 \mathrm{D}(\mathrm{culD}) \uparrow$ \\
\hline & - & calcium-binding protein (CBP2) $\uparrow$ \\
\hline & - & F-box A protein $(f b x A) \uparrow$ \\
\hline & - & hiwi $\uparrow$ \\
\hline & leucine-rich repeat-containing protein LRR (IrrA ) $\downarrow$ & leucine-rich repeat-containing protein LRR (IrrA ) $\downarrow$ \\
\hline & unknow $(s m / A) \downarrow$ & - \\
\hline & cisteine protease $4(\mathrm{cprD}, \mathrm{CP} 4) \downarrow$ & - \\
\hline & putative CMF receptor - CMFR1 ( $\mathrm{cmfB}) \downarrow$ & putative CMF receptor - CMFR1 ( $\mathrm{cmfB}) \downarrow$ \\
\hline & major vault protein $(m v p A) \downarrow$ & - \\
\hline & aquaporin like protein (wacA ) $\downarrow$ & - \\
\hline & G2/M - specific cyclin B $(c y c B) \downarrow$ & - \\
\hline & - & unknown (DG1008, sfbA ) $\downarrow$ \\
\hline & - & sulfite reductase $(\operatorname{red} A) \downarrow$ \\
\hline \multirow[t]{2}{*}{$12 \mathrm{~h}-\mathrm{H}_{2} \mathrm{O}_{2} \times 12 \mathrm{~h} \mathrm{H}_{2} \mathrm{O}_{2}$} & discoidin I, A chain $(d s c A) \downarrow$ & - \\
\hline & $12 \mathrm{kDa}$ protein $(c s b B) \downarrow$ & - \\
\hline
\end{tabular}

Genes with at least $60 \%$ of replicate points outside the cutoff limits in both biological samples were considered differentially expressed. The induced genes are represented by $\uparrow$ and the repressed genes by $\downarrow$.

of $p k a C, a c a A$ and carA found during development in low cell density (Figure 5, 6 and 7). The model includes the inhibition of pufA expression by yakA in response to starvation [2]. PufA seems to also have a role in the nitrosoative/oxidative stress response since in its absence the cells are more sensitive to these stresses [3]. The model also indicates yakA's regulation of the cell cycle through a pathway that is partially independent on pufA/pkaC/keaA to account for the fact that yakA null cells have a faster cell cycle which is not suppressed by second-site mutations in these genes. Furthermore, $p k a C^{-}$(act6::yakA) and $a c a^{-}$(act6::yakA) do not grow in liquid medium, showing that the arrest of growth is independent of $p k a C$ and acaA [1]. This may also explain the hypersensitivity observed for the yakA mutant to stress conditions that require growth arrest.

Our data implicates KeaA in the regulation of cAMP metabolism during development, but only when cells are starved in low cell density. kea $A$ is not required for fruiting body formation when cells are allowed to aggregate at high density. It may be that the aggregation phenotype is not so severe in $k e a A$ deficient cells due to the remaining $20 \%$ of expression of the truncated transcript that may yield some level of KeaA protein activity.

It is possible that KeaA acts as an adapter on the formation of a complex involved in cAMP synthesis. Kelch 
A.

B.
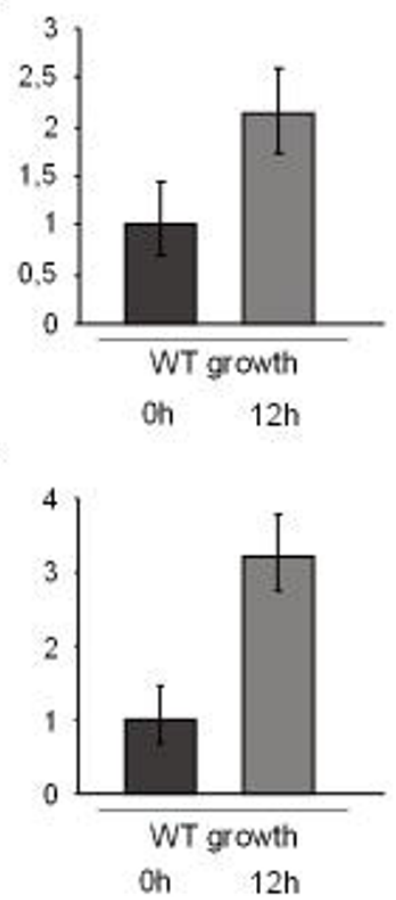

c.

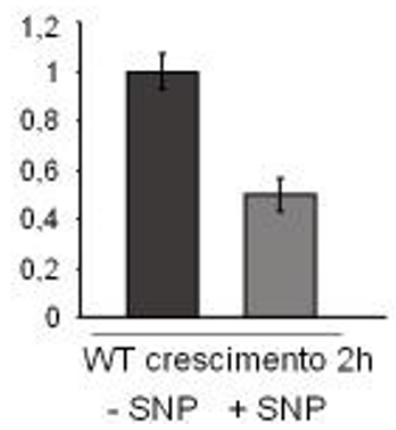

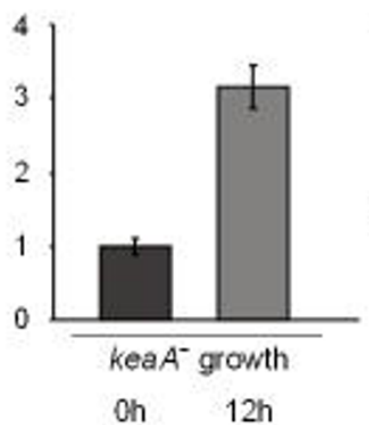
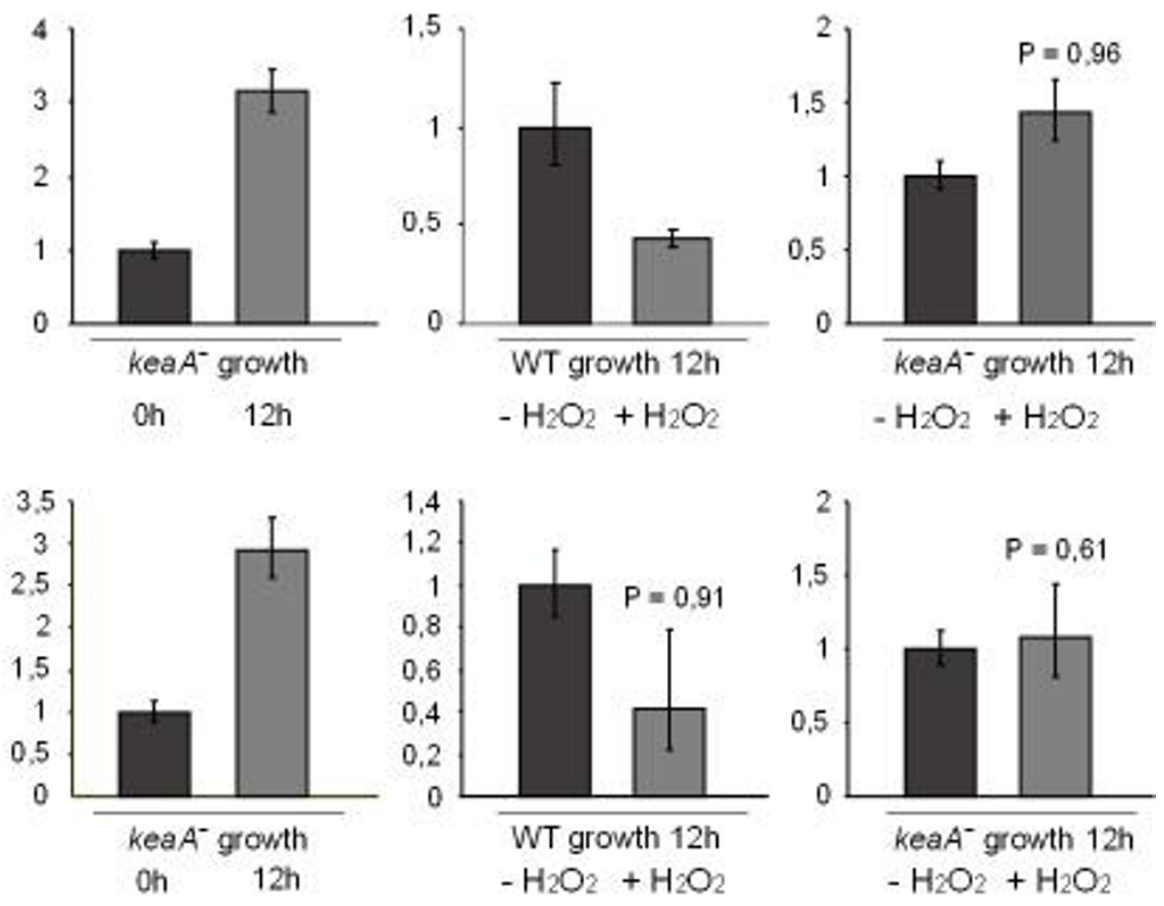

Figure 8 Validation of microarray data using real-time PCR for $\boldsymbol{d} \boldsymbol{s} \boldsymbol{A}$ and $\boldsymbol{c s} \boldsymbol{b} \boldsymbol{B}$. The y axis refers to the relative expression ratio between sample versus control. In black are represented the control samples. (A) Discoidin A (dscA), (B) Contact site B (csbB). The P value represents the statistical significance and was calculated in relation to the first time point.

domains have been implicated in protein-protein interactions and also in actin-cytoskeleton interactions [17]. In its absence, the signaling might still occur but with a less than optimal efficiency which might impair chemotaxis in low cell densities probably by affecting the establishment of polarity since this requires chemoattractant stimulation, a prerequisite for migration [28]. Further studies are necessary to determine if KeaA is required for cell polarization.

A mechanism for the activation of PKA by a Ga protein named Gpa2 was proposed in yeast. The activation appears to be accomplished trough the inhibition of two repeat proteins, Krh1 and Krh2, bypassing the direct regulation exerted by adenylate cyclase [29]. Gpa2 regulates PKA activity via two distinct pathways: through stimulation of adenylate cyclase [30,31], and through inhibition of the Krh proteins. Krh1 directly interacts with PKA by means of the catalytic subunits, and Krh1/ 2 stimulate the association between the catalytic and regulatory subunits in vivo [29]. Krh1/2 also enhance the association between mouse $\mathrm{R}$ and $\mathrm{C}$ subunits, suggesting a possible conservation of Krh control of PKA [29]. We have conducted tests using the twohybrid system to verify the interaction between PKA-C, PKA-R and KeaA but no interaction was observed (not shown). 

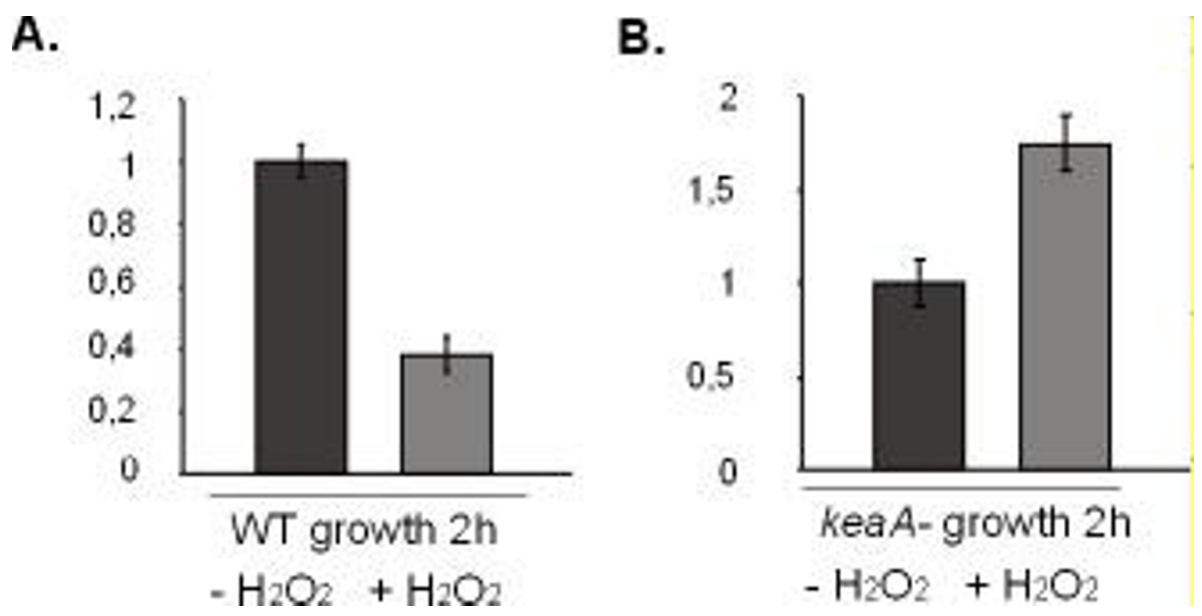

Figure 9 Validation of microarray data by real-time PCR for $\boldsymbol{c y} \boldsymbol{c} \boldsymbol{B}$. The y axis refers to the relative expression ratio between sample versus control. The control samples are represented in black. (A) WT, (B) keaA deficient cells.

On the other side the accumulation of intracellular cGMP and the transient polymerization of F-actin induced by folic acid stimulation has been shown to be absent in yak $A^{-}$cells [32]. The coupling of G-proteins to the cAMP receptor CarA did not seem to be affected by YakA, implicating that YakA may act downstream from CarA in the cAMP signaling pathway. KeaA may modulate this event. Since Kelch proteins have been seen to interact with actin in several other systems, it is possible that KeaA localizes to the membrane and directly interacts with the cAMP synthesis machinery, acting as an integral component of the spatially localized signaling that occurs at the cell cortex [33]. An investigation on the sub-cellular distribution of KeaA may help the biochemical characterization of its roles within the cell.

Kelch domain proteins participate in a wide variety of cellular processes. Originally they were identified in Drosophila associated with actin as a component of ring canals [16]. Kelch domains have been found in combination with a BTB/POZ or a Coiled/coil [17]. The association of a zf-C3HC4 domain (RING domain) with kelch domains, as seen in KeaA, is not common. Most of the kelch proteins found in metazoans are of the BTB/POZ variety [34]. RING domains appear to mediate proteinprotein interactions or the assembly of multi-protein complexes [19]. 5P24, a protein with a similar architecture (RING + Kelch domains) found in C. elegans [Genbank:NP 506602] has been found in large-scale RNAi experiments to be essential for male fertility [35]. Is interesting to note that the $C$. elegans Puf proteins FBF-1 and FBF-2 regulate germline sex determination [36] and germline stem cell maintenance [37]. As mentioned above, in Dictyostelium, the Puf protein PufA, was found as a suppressor of yakA's defects in development [2]. It is plausible that some of the same players responsible for decisions that lead to growth arrest and differentiation in Dictyostelium (yakA-pufA-keaA-pkaC) are at work in C. elegans.

A role for a kelch protein in the response to oxidative stresses has also been found in mice. The interaction of Keap1, Nrf2 and Cullin-3 forms an ubiquitin ligase substrate adaptor. Mutation of Keap1 leads to constitutive activation of $\mathrm{Nrf} 2$, upregulation of antioxidant genes, and resistance to electrophiles and oxidative stress [38]. On exposure to oxidative stress the sulfhydryl groups of Keap1 act as sensors. Modification of the cysteine thiols causes disruption of the Nrf2/Keap1 complex and migration of Nrf2 to the nucleus, where it induces expression of detoxifying and antioxidant genes $[39,40]$. Murine, rat and human Keap1 contains 25 reactive cysteines. The most reactive residues have been identified in the intervening region between the $\mathrm{BTB} / \mathrm{POZ}$ domain and the Kelch domains. Experiments that address the functional role of these cysteines are under way that might reveal a link between the redox state of the cell in the transition from growth to development and a possible role for ROS and NRS in the triggering of development.

The observation that $d s c A$ is repressed in response to treatment with $\mathrm{H}_{2} \mathrm{O}_{2}$ may be related to the fact that this treatment inhibits cell proliferation as does starvation. $d s c A$ expression is modulated by pre-starvation [41]. YakA has also been found to be involved in the regulation of the pre-starvation response [1]. dscA decrease may be controlled by cAMP and since keaA deficient cells do not accumulate cAMP in response to treatments with SNP and $\mathrm{H}_{2} \mathrm{O}_{2}$, the levels of $d s c A$ are kept high in keaA deficient cells treated with these compounds. Another gene that showed a similar expression profile was $c s b B$, a gene that as discoidin is involved in 


\section{Stress} (nutrient, RNS, ROS)

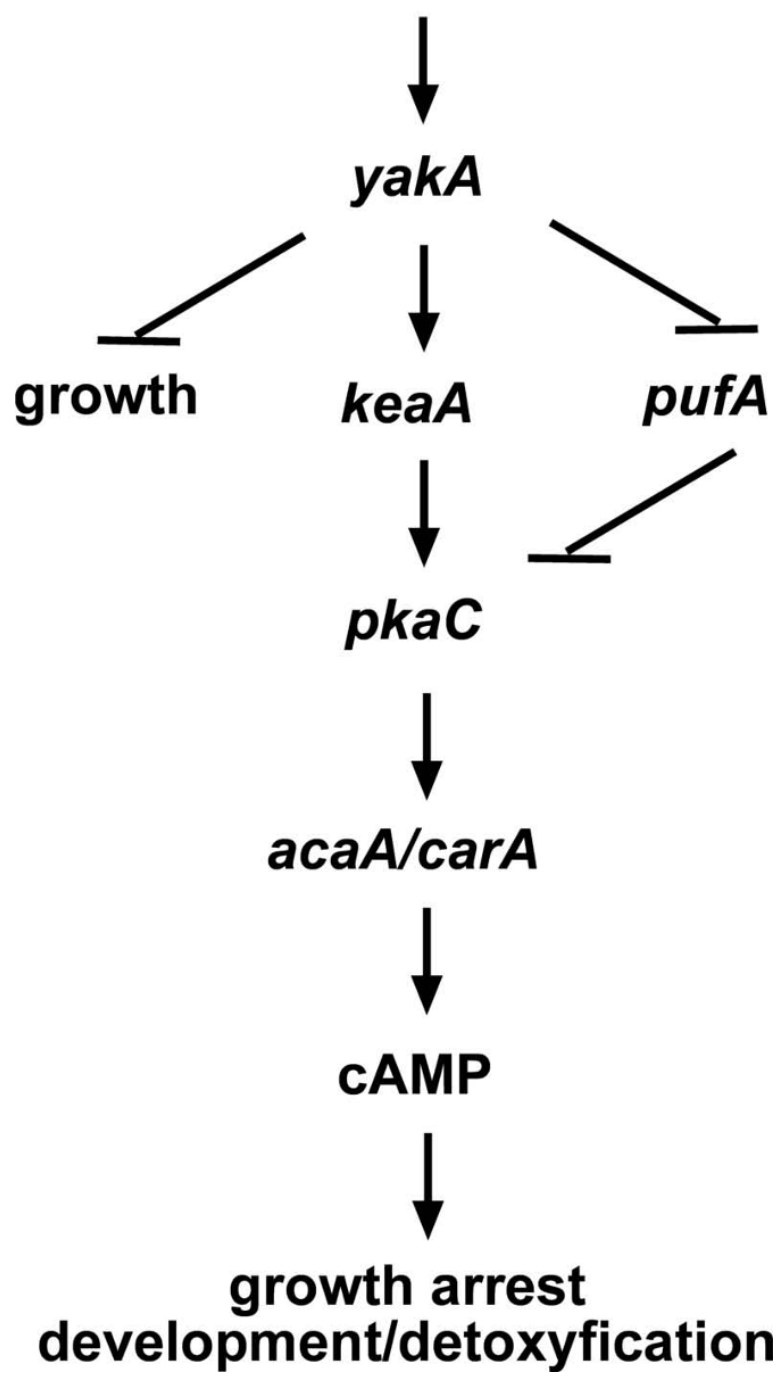

Figure 10 Pathways proposed to mediate Dictyostelium stress responses. The regulatory relationship between genes and events is described, with arrows representing a positive requirement for a gene or event and bars representing an inhibitory role.

cell adhesion. Cell cycle may also be de-regulated in the mutant, which may explain why keaA deficient cells do not stop growth in response to the stresses. In wild-type cells Cyclin B mRNA decreases while in keaA deficient cells the decrease is less prominent in response to SNP and actually increases in response to $\mathrm{H}_{2} \mathrm{O}_{2}$.

\section{Conclusions}

Our results indicate a role for KeaA in the regulation of Dictyostelium growth, development and stress survival. KeaA is required for cAMP signaling and the regulation of gene expression associated with the aggregation process. KeaA is also required for normal growth and oxidative/nitrosoative stress responses.

\section{Methods}

Cell strains

All strains are derived from the axenic Dictyostelium discoideum strain AX4 [42]. Mutant strains used were as follows: $p k a C$ null [43], acaA null [44], yakA null AK800 [1]. The original $y a k A / k e a A$ null strain isolated in the suppressor screen described by [3] was named 13-8. Regions flanking the plasmid insertion site in the REMImutant were isolated by plasmid rescue and the plasmid was named p13-8. The $y a k A / k e a A$ recapitulated null strain GMS121 was obtained by homologous recombination using plasmid p13-8. The same plasmid was used to disrupt keaA in the wild-type background (strain GMS122). The insertion is located between amino acids 1198 and 1199 of [Dictybase: DDB_G0271500]. The DG1106 isolate insertion was between amino acids 1041 and 1042 http://www-biology.ucsd.edu/others/dsmith/ dictydb.html.

\section{Growth, development and stress conditions for Dictyostelium cells}

All strains were grown in axenic media (HL-5) or on SM agar plates in the presence of Klebsiella aerogenes [45]. Treatments for survival rate scoring and growth curves were performed in fresh axenic cultures kept exponentially growing in HL-5 for one week. For both cases cells were collected at $1-2 \times 10^{6} / \mathrm{mL}$, diluted to $0.5-1 \times 10^{6} / \mathrm{mL}$ in HL-5 and $500 \mu \mathrm{M} \mathrm{H}_{2} \mathrm{O}_{2}$ or $500 \mu \mathrm{M}$ sodium nitroprusside (SNP) were added. Cells were counted with the aid of a hemocytometer. Growth curves for mutants were determined in side-by-side tests with non-mutant sibling transformants. Survival rates were determined by counting the cells after the treatments, plating in association with Klebsiella aerogenes and counting the colonies formed.

For preparation of clearing plates, $3 \times 10^{5}$ cells were plated with $0.4 \mathrm{~mL}$ of an overnight culture of bacteria over SM plates. For development on agar plates, cells were washed twice in $20 \mathrm{mM}$ potassium phosphate buffer $\mathrm{pH} 6.4$ and plated on 1\% agar dissolved in the same buffer. Cells were developed on nitrocellulose filters as described [45]. For cAMP pulsing experiments, cells were washed in $20 \mathrm{mM} \mathrm{KPO}_{4} \mathrm{pH}$ 6.4, ressuspended to $1 \times 10^{6}$ cells $/ \mathrm{mL}$ in the same buffer and shaken at 100 rpm for 2 hours, followed by pulses of cAMP to $80 \mathrm{nM}$ at 6-minute intervals.

\section{Transformation}

REMI mutagenesis was carried out in the yakA null background (strain AK800) as described [3]. Confirmation 
that a mutation in $k e a A$ was responsible for the resistance to SNP treatment observed in the 13-8 strain was done by recapitulation of the resistance phenotype by disruption of the gene in the yakA null background. Homologous recombination was carried out by electroporation of $y a k A$ null and wild-type cells with $40 \mu \mathrm{g}$ of p13-8 digested with ClaI. Transformants were selected in HL-5 supplemented with $4 \mu \mathrm{g} / \mathrm{mL}$ Blasticidin.

\section{Isolation of suppressors}

The screen for mutations that suppress the yakA-null sensitivity to SNP was carried out as described [3]. The YakA-null mutant AK800, which harbors a plasmid insertion (IS800) in the sequence that encodes the protein kinase core [1], was used as the parental strain for insertional mutagenesis. A REMI-mutagenized population of 70,000 clones was diluted to $5 \times 10^{5}$ cells $/ \mathrm{mL}$ in HL-5 supplemented with $500 \mu \mathrm{M}$ SNP. The cells were shaken at $22^{\circ} \mathrm{C}$ for 10 days, after which time cells were diluted and plated in association with Klebsiella aerogenes for clone isolation.

\section{DNA and RNA manipulations}

Standard DNA and RNA manipulations were carried out as described [46]. Genomic DNA from the suppressor mutant was extracted and flanking genomic DNA was recovered from strain 13-8 by plasmid rescue with ClaI to liberate a $4.9 \mathrm{~kb}$ fragment which was cloned as described [47]. Plasmid p13-8 was sequenced and the insertion mapped to the open reading frame of gene DG1106 (accession number AF111942). Recapitulation by homologous recombination at the keaA locus using plasmid p13-8 was confirmed by digestion of genomic DNA from candidate clones with EcoRI and hybridization with a ClaI fragment probe on Southern blots. RNA was extracted using the Trizol reagent as described by the manufacturer (Life Technologies). The DNA fragments used as probes on northern blots were as follows: an EcoRI fragment containing the full length cDNA for $\operatorname{car} A$, a BamHI/HindIII fragment of $p k a C$ that excludes the repeats at the $\mathrm{N}$-terminus of the protein.

\section{Biochemical analysis}

cAMP measurements were carried out using the BIOTRAK cAMP ${ }^{125}$ I Assay System (dual range) (Amersham Pharmacia Biotech). Samples were prepared from cells diluted to $1 \times 10^{6} / \mathrm{mL}$ in HL-5 media with or without SNP or $\mathrm{H}_{2} \mathrm{O}_{2}$. After treatment, $5 \times 10^{6}$ cells were spun down, ressuspended in $100 \mu \mathrm{L}$ of phosphate buffer, added to $100 \mu \mathrm{L}$ of $3.5 \%$ perchloric acid and frozen. Before analysis frozen samples were thawed and neutralized with $50 \% \mathrm{NaHCO}_{3}$. The resulting lysates were centrifuged and the supernatants assayed.

\section{DNA and protein sequence analyses}

Clone 13-8 sequence was compared to the sequences present in the databanks using the BLAST search program [48] and indicated complete identity to the DG1106 amino acid and nucleotide sequences deposited in Genbank under the accession number AF111942.

\section{cDNA microarrays}

Probes were amplifyed by PCR directly from bacterial clones in culture. Microarrays were constructed by arraying cDNA fragments on metal-coated glass slides (Type 7, Amersham Biosciences). Each cDNA fragment was spotted on the slides at least twelve times (i.e., technical replicates). The arrays contain 237 genes represented. Following printing, the slides were allowed to dry and spotted DNA was bound to the slides by UV cross-linking. RNA extracted from wild-type and keaA deficient cells treated or not with SNP or $\mathrm{H}_{2} \mathrm{O}_{2}$. Samples from two independent experiments (i.e., biological samples) were used for the synthesis of fluorescent targets with Cy3 or Cy5.

\section{Data analysis of cDNA microarrays}

Slides were scanned, images were processed and data collected using the ArrayVision (Imaging Research, Inc.) software. The data were extracted and normalized by Lowess fitting [49]. We used homotypic hibridizations of the reference sample to define intensity-dependent cutoff levels that would indicate differentially expressed genes as described [50]. Genes with at least $60 \%$ of the replicate points above or below the cutoff limits were considered differentially expressed in that particular sample [50].

\section{Quantitative PCR}

RNA was treated with DNAse and used for transcription reverse reactions. The quantitative PCR reactions were carried out using the SYBR Green PCR Master Mix (Applied Biosystems) in a GeneAmp 5700 Sequence Detection System (Applied Biosystems). qRT-PCR assays were performed with the following gene-specific primer pairs: keaA: TTGAAACTTGGGAATGGGAAA and CAGCTAAAACCTCAGAAAAGTAACCA, IG7: GTGG TTCGGCACCTCGAT and CACCCCAACCCTTGGA AA, $d s c A$ : GGTGCTGCTGTTACTGGTGT and GGTGG ATAGCAATTGAACGA, pkaC: TTTGGCACCTGAAAT CATTC and AAGGTGGATAACCTGCCAAC, pkaR: GGT GAG GTT ATT GTG CGT CAA G and GTG ACA ACA ACT TTA CCT TCA ACG A, acaA : TCCTTTGGT TGCTGGTTGTA and TCTTGAGCATTGGATTGCAT, carA: ATGTTTCCACCAGCACTCAA and AAATGTGACAGATGCCCAAA, $c s b B$ : TGAAGATGGGGAATCAACAA and GGAAATATTTGGGGAGCTGGT, $c y c B$ : 
GTCCACAAATCAAGGATTTCGTT and ATTTGT CTTTCCATGTCGATAACCT. The specificity of the amplified products was evaluated through the analysis of the dissociation curves generated by the equipment. The data and error bars were calculated as described by Livak and Schmittgen [51]. To access the statistical significance of expression ratios, we assumed a log-normal model and calculated the probability $\mathrm{P}=\operatorname{Pr}$ (sample $>$ reference) and $\mathrm{P}=\operatorname{Pr}$ (sample $<$ reference). We consider expression levels to differ the reference sample on each experiment when $\mathrm{P} \geq 0.95[50,52]$.

\section{List of abbreviations used}

SNP: sodium nitroprusside; RNS: reactive nitrogen species; ROS: reactive oxygen species.

\section{Acknowledgements}

This work was supported by Fundação de Amparo à Pesquisa do Estado de São Paulo. We are indepted to Fernando Toshio Ogata and Leila Kazokas for their valuable help with some of the experimentation. We thank the Dictyostelium cDNA Project in Japan for CDNA clones. GMS is recipient of a CNPq Fellowship.

\section{Authors' contributions}

LM and RB carried out most of the experimental work. GMS coordinated the study, participated in its design and wrote the manuscript. All authors read and approved the final manuscript.

Received: 21 May 2009 Accepted: 29 July 2010 Published: 29 July 2010

\section{References}

1. Souza GM, Lu S, Kuspa A: YakA, a protein kinase required for the transition from growth to development in Dictyostelium. Development 1998, 125:2291-2302.

2. Souza GM, da Silva AM, Kuspa A: Starvation promotes Dictyostelium development by relieving PufA inhibition of PKA translation through the YakA kinase pathway. Development 1999, 126:3263-3274.

3. Taminato A, Bagattini R, Gorjao R, Chen G, Kuspa A, Souza GM: Role for YakA, cAMP, and protein kinase $A$ in regulation of stress responses of Dictyostelium discoideum cells. Mol Biol Cell 2002, 13:2266-2275.

4. Firtel RA: Interacting signaling pathways controlling multicellular development in Dictyostelium. Curr Opin Genet Dev 1996, 6:545-554.

5. Loomis WF: Role of PKA in the timing of developmental events in Dictyostelium cells. Microbiol Mol Biol Rev 1998, 62:684-694.

6. Schulkes C, Schaap P: CAMP-dependent protein kinase activity is essential for preaggregative gene expression in Dictyostelium. FEBS Lett 1995, 368:381-384

7. Mann SK, Brown JM, Briscoe C, Parent C, Pitt G, Devreotes PN, Firtel RA: Role of CAMP-dependent protein kinase in controlling aggregation and postaggregative development in Dictyostelium. Dev Biol 1997, 183:208-221.

8. Broach JR, Deschenes RJ: The function of ras genes in Saccharomyces cerevisiae. Adv Cancer Res 1990, 54:79-139.

9. Wang Y, Pierce M, Schneper L, Guldal CG, Zhang X, Tavazoie S, Broach JR: Ras and Gpa2 mediate one branch of a redundant glucose signaling pathway in yeast. PLOS Biol 2004, 2:E128.

10. Santangelo GM: Glucose signaling in Saccharomyces cerevisiae. Microbiol Mol Biol Rev 2006, 70:253-282.

11. Boy-Marcotte E, Perrot M, Bussereau F, Boucherie H, Jacquet M: Msn2p and Msn4p control a large number of genes induced at the diauxic transition which are repressed by cyclic AMP in Saccharomyces cerevisiae. J Bacteriol 1998, 180:1044-1052

12. Gorner W, Durchschlag E, Martinez-Pastor MT, Estruch F, Ammerer G, Hamilton B, Ruis $\mathrm{H}$, Schuller $\mathrm{C}$ : Nuclear localization of the $\mathrm{C} 2 \mathrm{H} 2$ zinc finger protein Msn2p is regulated by stress and protein kinase A activity. Genes Dev 1998, 12:586-597.
13. Fernandes $L$, Rodrigues-Pousada C, Struhl $K$ : Yap, a novel family of eight bZIP proteins in Saccharomyces cerevisiae with distinct biological functions. Mol Cell Biol 1997, 17:6982-6993.

14. Charizanis $C$, Juhnke $H$, Krems B, Entian KD: The oxidative stress response mediated via Pos9/Skn7 is negatively regulated by the Ras/PKA pathway in Saccharomyces cerevisiae. Mol Gen Genet 1999, 261:740-752.

15. Hasan R, Leroy C, Isnard AD, Labarre J, Boy-Marcotte E, Toledano MB: The control of the yeast $\mathrm{H} 2 \mathrm{O} 2$ response by the Msn2/4 transcription factors. Mol Microbiol 2002, 45:233-241.

16. Xue F, Cooley L: kelch encodes a component of intercellular bridges in Drosophila egg chambers. Cell 1993, 72:681-693.

17. Adams J, Kelso R, Cooley L: The kelch repeat superfamily of proteins: propellers of cell function. Trends Cell Biol 2000, 10:17-24.

18. Ito N, Phillips SE, Yadav KD, Knowles PF: Crystal structure of a free radical enzyme, galactose oxidase. J Mol Biol 1994, 238:794-814.

19. Saurin AJ, Borden KL, Boddy MN, Freemont PS: Does this have a familiar RING? Trends Biochem Sci 1996, 21:208-214.

20. Lorick KL, Jensen JP, Fang S, Ong AM, Hatakeyama S, Weissman AM: RING fingers mediate ubiquitin-conjugating enzyme (E2)-dependent ubiquitination. Proc Natl Acad Sci USA 1999, 96:11364-11369.

21. Otto GP, Wu MY, Kazgan N, Anderson OR, Kessin RH: Macroautophagy is required for multicellular development of the social amoeba Dictyostelium discoideum. J Biol Chem 2003, 278:17636-17645.

22. Glockner G, Eichinger L, Szafranski K, Pachebat JA, Bankier AT, Dear PH, Lehmann R, Baumgart C, Parra G, Abril JF, Guigó R, Kumpf K, Tunggal B, Cox E, Quail MA, Platzer M, Rosenthal A, Noegel AA: Sequence and analysis of chromosome 2 of Dictyostelium discoideum. Nature 2002, 418:79-85.

23. Kuspa A, Loomis WF: Tagging developmental genes in Dictyostelium by restriction enzyme-mediated integration of plasmid DNA. Proc Natl Acad Sci USA 1992, 89:8803-8807.

24. Wang B, Kuspa A: Dictyostelium development in the absence of cAMP. Science 1997, 277:251-254.

25. Clarke M, Kayman SC, Riley K: Density-dependent induction of discoidin-I synthesis in exponentially growing cells of Dictyostelium discoideum. Differentiation 1987, 34:79-87.

26. Blusch J, Alexander S, Nellen W: Multiple signal transduction pathways regulate discoidin I gene expression in Dictyostelium discoideum. Differentiation 1995, 58:253-260.

27. Endl I, Konzok A, Nellen W: Antagonistic effects of signal transduction by intracellular and extracellular cAMP on gene regulation in Dictyostelium. Mol Biol Cell 1996, 7:17-24.

28. Kriebel PW, Barr VA, Parent CA: Adenylyl cyclase localization regulates streaming during chemotaxis. Cell 2003, 112:549-560.

29. Peeters T, Louwet W, Gelade R, Nauwelaers D, Thevelein JM, Versele M: Kelchrepeat proteins interacting with the Galpha protein Gpa2 bypass adenylate cyclase for direct regulation of protein kinase $\mathrm{A}$ in yeast. Proc Natl Acad Sci USA 2006, 103:13034-13039.

30. Colombo S, Ma P, Cauwenberg L, Winderickx J, Crauwels M, Teunissen A, Nauwelaers D, de Winde JH, Gorwa MF, Colavizza D, Thevelein JM: Involvement of distinct G-proteins, Gpa2 and Ras, in glucose- and intracellular acidification-induced cAMP signalling in the yeast Saccharomyces cerevisiae. Embo J 1998, 17:3326-3341.

31. Lorenz MC, Heitman J: Yeast pseudohyphal growth is regulated by GPA2, a G protein alpha homolog. Embo J 1997, 16:7008-7018.

32. van $E S S$, Weening KE, Devreotes PN: The protein kinase YakA regulates $g$ protein- linked signaling responses during growth and development of Dictyostelium. J Biol Chem 2001, 276:30761-30765.

33. Kimmel AR, Parent CA: The signal to move: $\mathrm{D}$. discoideum go orienteering. Science 2003, 300:1525-1527.

34. Prag S, Adams JC: Molecular phylogeny of the kelch-repeat superfamily reveals an expansion of BTB/kelch proteins in animals. BMC Bioinformatics 2003, 4:42.

35. Kamath RS, Fraser AG, Dong Y, Poulin G, Durbin R, Gotta M, Kanapin A, Le Bot N, Moreno S, Sohrmann M, Welchman DP, Zipperlen P, Ahringer J: Systematic functional analysis of the Caenorhabditis elegans genome using RNAi. Nature 2003, 421:231-237.

36. Zhang B, Gallegos M, Puoti A, Durkin E, Fields S, Kimble J, Wickens MP: A conserved RNA-binding protein that regulates sexual fates in the C. elegans hermaphrodite germ line. Nature 1997, 390:477-484. 
37. Crittenden $S L$, Bernstein DS, Bachorik JL, Thompson BE, Gallegos M, Petcherski AG, Moulder G, Barstead R, Wickens M, Kimble J: A conserved RNA-binding protein controls germline stem cells in Caenorhabditis elegans. Nature 2002, 417:660-663.

38. Hayes JD, MCMahon M: NRF2 and Keap1 mutations: Permanent actication of an adaptive response in cancer. Trends Biochem Sci 2009, 34:176-188.

39. Itoh K, Wakabayashi N, Katoh Y, Ishii T, Igarashi K, Engel JD, Yamamoto M: Keap1 represses nuclear activation of antioxidant responsive elements by Nrf2 through binding to the amino-terminal Neh2 domain. Genes Dev 1999, 13:76-86.

40. Dinkova-Kostova AT, Holtzclaw WD, Cole RN, Itoh K, Wakabayashi N, Katoh Y, Yamamoto M, Talalay P: Direct evidence that sulfhydryl groups of Keap1 are the sensors regulating induction of phase 2 enzymes that protect against carcinogens and oxidants. Proc Natl Acad Sci USA 2002, 99:11908-11913.

41. Clarke M, Yang J, Kayman SC: Analysis of the prestarvation response in growing cells of Dictyostelium discoideum. Developmental genetics 1988, 9:315-326

42. Knecht DA, Cohen SM, Loomis WF, Lodish HF: Developmental regulation of Dictyostelium discoideum actin gene fusions carried on low-copy and high-copy transformation vectors. Mol Cell Biol 1986, 6:3973-3983.

43. Mann SK, Firtel RA: A developmentally regulated, putative serine/ threonine protein kinase is essential for development in Dictyostelium. Mech Dev 1991, 35:89-101.

44. Pitt GS, Milona N, Borleis J, Lin KC, Reed RR, Devreotes PN: Structurally distinct and stage-specific adenylyl cyclase genes play different roles in Dictyostelium development. Cell 1992, 69:305-315.

45. Sussman M: Cultivation and synchronous morphogenesis of Dictyostelium under controlled experimental conditions. Methods Cell Biol 1987, 28:9-29

46. Sambrook J, Fritsch EF, Maniatis T: Molecular Cloning: A Laboratory Manual Cold Spring Harbor, NY: Cold Spring Harbor Laboratory 1989.

47. Kuspa A, Loomis WF: Transformation of Dictyostelium - gene disruptions, insertional mutagenesis, and promoter traps. Methods Mol Genet 1994, 3:3-21.

48. Altschul SF, Madden TL, Schaffer AA, Zhang J, Zhang Z, Miller W, Lipman DJ: Gapped BLAST and PSI-BLAST: a new generation of protein database search programs. Nucleic Acids Res 1997, 25:3389-3402.

49. Yang YH, Dudoit S, Luu P, Lin DM, Peng V, Ngai J, Speed TP: Normalization for cDNA microarray data: a robust composite method addressing single and multiple slide systematic variation. Nucleic Acids Res 2002, 30:e15.

50. Rocha FR, Papini-Terzi FS, Nishiyama MY, Vencio RZ, Vicentini R, Duarte RD, de Rosa VE, Vinagre F, Barsalobres C, Medeiros AH, et al: Signal transduction-related responses to phytohormones and environmental challenges in sugarcane. BMC genomics 2007, 8:71.

51. Livak KJ, Schmittgen TD: Analysis of relative gene expression data using real-time quantitative PCR and the 2(-Delta Delta $\mathrm{C}(\mathrm{T})$ ) Method. Methods 2001, 25:402-408.

52. Papini-Terzi FS, Rocha FR, Vencio RZ, Felix JM, Branco DS, Waclawovsky AJ, Del Bem LE, Lembke CG, Costa MD, Nishiyama MY, et al: Sugarcane genes associated with sucrose content. BMC genomics 2009, 10:120.

doi:10.1186/1471-213X-10-79

Cite this article as: Mantzouranis et al: KeaA, a Dictyostelium kelchdomain protein that regulates the response to stress and development. BMC Developmental Biology 2010 10:79.

\section{Submit your next manuscript to BioMed Central and take full advantage of:}

- Convenient online submission

- Thorough peer review

- No space constraints or color figure charges

- Immediate publication on acceptance

- Inclusion in PubMed, CAS, Scopus and Google Scholar

- Research which is freely available for redistribution

Submit your manuscript at www.biomedcentral.com/submit
Biomed Central 